\title{
LXXXIII. Characters of some undescribed sSpecies of Araneidæ
}

\author{
John Blackwall Esq. F.L.S.
}

To cite this article: John Blackwall Esq. F.L.S. (1836) LXXXIII. Characters of some undescribed sSpecies of Araneidæ, Philosophical Magazine Series 3, 8:49, 481-491, DOI: 10.1080/14786443608648925

To link to this article: http://dx.doi.org/10.1080/14786443608648925

册 Published online: 01 Jun 2009.

Submit your article to this journal $\lceil\pi$

ЏII Article views: 2

Q View related articles $\square$ 
Mr. Blackwall on undescribed Species of Araneidæ. 481 vations in defect by an unknown constant quantity $x$, the calculated refraction for the arc $a$ will be $\frac{a}{r}-x$, and that for the arc $\mathrm{C}, \frac{c}{r}-x$. Hence the true refraction for the intermediate arc $b$ must equal the difference of these two qua $n$ tities, and the constant error of the instrument will be the excess of this proportion of the arc $c$ (or $a$ ) above the quantity previously calculated.

The several values of the refraction in terms of the arc, and that of the error of the instrument, deduced from the application of the above formula to various combinations of the four classes of arcs, are subjoined.

$$
\begin{aligned}
& \text { Ref. } \quad \begin{array}{c}
\text { Error of } \\
\text { Sector. }
\end{array} \\
& \text { I. By the difference of } \mathrm{B} \text { and A } \ldots \frac{1}{1 \frac{1}{5} \cdot 5} \quad-24^{\prime \prime} \\
& \text { II. ——C and A ... } \frac{1 \frac{1}{15} 7}{\square} \quad-23 \\
& \text { III. _ _ D and A ... } \frac{1}{15} \quad-26 \\
& \text { IV. }
\end{aligned}
$$

The true value of the mean refraction is most probably the average of the two first ratios, or ${ }_{1 \frac{1}{5} \cdot \frac{6}{6}}$, and that of the instrumental error $23 \frac{11}{2}$, or about $2^{\prime \prime}$ more than the quantity derived from actual measurement. (See Lond. and Edinb. Phil. Mag. for 1833, vol. ii. page 334.)

Ilkley, April 27, 1836.

John Nixon.

LXXXIII. Characters of some undescribed Species of Araneidæ. By Joh i Blackwall, Esq., F.L.S., \& c.*

$$
\left.\begin{array}{l}
\text { Tribe, TuBIтEL王, Latreille. } \\
\text { Genus, Walckenaëria } \\
\text { Walckenaëria fuscipes, }
\end{array}\right\} \text { mihi. }
$$

CEPHALOTHORAX oval, convex and glossy, with a slight indentation in the medial line of the posterior region; the anterior part, which is prominent and acute, is compressed and deeply indented on the sides, and has also a slight longitudinal indentation above : in front it is divided into two segments by a transverse groove. Mandibles conical, armed with teeth on the inner surface, and inclined towards the pectus, which is broad and heart-shaped. Legs moderately robust; the anterior and posterior pairs, which are the longest, are equal in length, and the third pair is the shortest. These parts, with the maxillæ and lip, are of a brown colour ; palpi brown, the fourth and fifth joints being much the darkest; the fourth joint terminates in two apophyses; one, which is large, depressed, and hairy externally, overlaps the base of the fifth joint; the other, which is small, projects on the inner side; the fifth joint is oval, convex and hairy externally, concave within, comprising the palpal organs; they are higbly

* Communicated by the Author.

Third Series. Vol.8. No.49. June 1836. 


\section{Mr. Blackwall on undescribed Species of Araneidæ.}

developed, not very complex in structure, and are of a brown colour tinged with red. Eyes distributed in pairs on the anterior eminence of the cephalothorax ; one pair is situated on the summit of its superior segment, another on a small prominence on the upper part of the inferior segment, in front; these eyes describe a narrow trapezoid whose shortest side is before; the third and fourth pairs are seated on the sides of the frontal eminence, and are geminated. Each tarsus is terminated by three claws; the two upper ones are pectinated, and the lower one is inflected near its base. Abdomen oval, convex above, projecting over the base of the cephalothorax ; it is thinly covered with hair, glossy, and of a brownish black colour. The plates of the spiracles are pale yellow.

Length, from the anterior part of the cephalothorax to the extremity of the abdomen, $\frac{1}{12}$ th of an inch; length of the cephalothorax $\frac{1}{g}$; breadth $\frac{1}{3}$; breadth of the abdomen $\frac{1}{3 \frac{1}{3}}$; length of an anterior leg $\frac{1}{0}$; length of a leg of the third pair $\frac{1}{12}$.

I found this spider in March 1835, at Oakland, under stones; but obtained specimens of males only.

\section{Walckenaëria depressa.}

Cephalothorax of a short oval form, convex, prominent, but obtuse, before, where the eyes are situated, depressed in the posterior region, without any indentation in the medial line. Mandibles moderately strong, concave, and slightly inclined towards the pectus, which is broad and heart-shaped. The anterior and posterior pairs of legs, which are the longest, are equal in length, and the third pair is the shortest. These parts, with the maxilla and lip, are of a deep brown colour, the cephalothorax, pectus, and lip being much the darkest. Each tarsus is terminated by three claws; the two superior ones are curved and pectinated, and the inferior one is inflected near its base. The third and fourth joints of the palpi are short; the latter is the larger, and has two strong apophyses in front, the outer one of which is the more prominent: the fifth joint is oval, convex and hairy externally, concave within, comprising the palpal organs; they are highly developed, complicated in structure, with a curved, spiny process at the extremity, and are of a deep red-brown colour. Abdomen oval, somewhat depressed, pointed at the spinners, and projects over the base of the cephalothorax ; it is thinly covered with hair, glossy, and brownish black. Plates of the spiracles deep brown. Aged individuals have the legs of a dark red-brown colour.

Length, from the anterior part of the cephalothorax to the extremity of the abdomen, $T^{1}$ th of an inch ; length of the cephalothorax $\frac{1}{28}$; breadth $\frac{1}{32}$; breadth of the abdomen $\frac{1}{27}$; length of an anterior leg $\frac{1}{1} \mathrm{r}$; length of a leg of the third pair $\frac{1}{1}$.

The specimens from which the description was made were taken under stones, in a wood at Oakland, in April 1835. Males alone were captured.

\section{Walckenaëria obtusa.}

There is a striking resemblance between the male of this species and the male of Walckenaëria cuspidata*; the following are the principal points of difference. The male of Walckenaëria obtusa is decidedly the larger, its pectus is more elongated, it has a slight indentation in the medial line of the posterior region of the cephalothorax, and bas no acute, conical prominence situated within the trapezoid formed by the four intermediate

* For the description of Walckenaëria cuspidata, see Lond. and Edinb. Phil. Mag., vol. iii. p. 108. 
eyes. Its palpi also differ a little in organization : the third joint is clavate; the fourth is short, terminating in three apophyses, the largest of which curves outwards before the fifth joint; exterior to this occurs the next in size, having a small, pointed prominence at its base, in front; and the smallest is situated underneath: the fifth joint is somewhat oval, convex and hairy externally, concave within, comprising the palpal organs; they are highly developed, complicated in structure, with a strong spine on the outer side curved into a circular form, and are of a brownish black colour tinged with red.

Length, from the anterior part of the cephalothorax to the extremity of the abdomen, $\frac{1}{7}$ th of an inch; length of the cephalothorax $\frac{1}{5} ;$ breadth $\frac{1}{20}$; breadth of the abdomen $\frac{1}{19}$; length of an anterior leg $\frac{5}{z^{5}}$; length of a leg of the third pair $\frac{1}{6}$.

I found males of this species under stones at Oakland in February 1835; but I have not been so fortunate as to discover the female.

\section{Tribe, Inequitede, Latreille. Genus, Theridion, Walckenaër. Theridion angulatum.}

Cephalothorax inversely heart-shaped, inclining to oval, convex, slightly hairy, prominent before, where the eyes are situated, with an indentation in the medial line of the posterior region; its colour is pale yellowbrown, with a longitudinal band of red-brown on each side, and a broader one of the same hue extending along the middle; the margins are yellowish white. Eyes placed on black spots; four, which are intermediate, form a square nearly, the two in front being seated on a protuberance; the other four are disposed in pairs on the sides of the square; the eyes constituting each pair are placed obliquely on an eminence, and are near together but not contiguous. Mandibles moderately strong, conical, and perpendicular; they are red-brown, with a spot of a darker hue in front, near the base of each. Maxillæ enlarged externally, where the palpi are inserted, obliquely truncated on the outer side, at the extremity, and inclined towards the lip, which is almost semicircular, being a little pointed at the apex. These organs, and the palpi, which are short, and are armed with a curved, pectinated claw at the extremity, are of a red-brown colour. Pectus of an oblong heart-shape and a dark red-brown hue. Legs yellowish-brown banded with red-brown; the first pair is the longest, then the fourth, the third pair being the shortest; the second and third pairs are disproportionally short. Each tarsus is terminated by three claws; the two superior ones are curved, and are slightly pectinated near the base, and the inferior one is inflected near its insertion. The abdomen, which is deeply notched in front, and projects over the base of the cephalothorax, has an angular appearance, occasioned by two, bold, lateral prominences, situated on the upper side, nearer to the posterior than the anterior extremity; the superior surface, from the fore part to the lateral prominences, is of a deep red-brown colour, the margins being the darkest; on each side of the medial line are two minute, yellowish white spots, forming a long narrow quadrangle; the posterior part is pale red-brown, a yellow transverse line connecting the two lateral prominences, from which proceed two obscure, angular bands that converge to the spiuners; the whole of the upper part has an irregular border of yellowish-white minutely freckled with red-brown; the sides and under part of the abdomen are dark red-brown, with streaks and minute spots of a lighter shade. Plates of the spiracles yellow.

Length, from the anterior part of the cephalothorax to the extremity of $3 \mathrm{C} 2$ 


\section{Mr. Blackwall on undescribed Species of Araneidæ.}

the abdomen, $\frac{1}{7}$ th of an inch ; length of the cephalothorax $\frac{1}{16}$; breadth $\frac{1}{2}$; breadth of the abdomen $\frac{1}{14}$; length of an anterior leg $\frac{1}{x}$; length of a leg of the third pair $\frac{1}{8}$.

This spider, which, like Tetragnatha extensa, frequently extends the first and second pairs of legs forwards, and the third and fourth pairs backwards, in a line with the body, was found in a cleft of a rail at Oakland, in the month of April, 1835. I have not yet seen the male.

\section{Theridion filipes.}

This remarkable species has the cephalothorax of an oval form; it is convex and glossy, with an indentation in the medial line of the posterior region. Mandibles powerful, conical, armed with teeth on the inner surface, rather divergent at the extremities, and inclined towards the pectus, which is heart-shaped. Maxillæ enlarged at the base, where the palpi are inserted, obliquely truncated on the outer side, at the extremity, and inclined towards the lip, which is semicircular, and prominent at the apex. Legs and palpi long, slender, and furnished with hairs and some fine, erect spines. These parts are of a brown colour, the mandibles and maxilla having a tinge of red. Eyes disposed in two transverse rows on the fore part of the cephalothorax; the intermediate eyes of both rows form a trapezoid whose anterior side is considerably the shortest; the lateral ones are placed obliquely in pairs, each pair being seated on a small eminence, and geminated; the posterior eyes of the trapezoid are larger, and the anterior ones much smaller than the rest. Each tarsus is terminated by three claws; the two superior ones are curved and slightly pectinated, and the inferior one is inflected near its base. The first pair of legs is the longest, then the fourth, the third pair being the shortest. Abdomen oval, convex above, projecting over the base of the cephalothorax; it is thinly covered with hair, glossy, and of a blackish brown colour, with a tinge of olive. A long, slender, cylindrical, semitransparent process, directed backwards, is in connexion with the sexual organs. Plates of the spiracles of a deep, dull brown colour. Some specimens have a series of faint, pale, angular lines, whose vertices are directed forwards, extending along the middle of the upper part of the abdomen.

Length, from the anterior part of the cephalothorax to the extremity of the abdomen, $\frac{1}{9}$ th of an inch ; length of the cephalothorax $\frac{1}{3}$; breadth $\frac{1}{30}$; breadth of the abdomen $\frac{1}{1} ;$; length of an anterior leg $\frac{5}{2} ;$; length of a leg of the third pair $\frac{3}{2 \pi}$.

The male is rather smaller and darker coloured than the female, but the relative length of its legs is the same; their absolute length, however, is greater, an anterior one measuring $\frac{1}{4} \frac{1}{8}$ ths of an inch. The third and fourth joints of the palpi are short; the latter, which is the stronger, being prominent on the inner side and in front; with the frontal prominence several long bristles are connected : the fifth joint is of a long, irregular oval form, having a projection on the outer side, and two smaller ones on the upper part, near its articulation with the fourth joint; it is convex and hairy externally, concave within, comprising the palpal organs, which are highly developed, complicated in structure, and of a red-brown colour; a strong, corneous spine, enveloped in a delicate, transparent membrane, originates in the upper part of these organs, and, bending downwards, extends along their inner side a little beyond the termination of the fifth joint, being curved outwards at its extremity.

This spider is allied to the Nerience by the disposition and relative size of the eyes, and to the Linyphice by the length and delicacy of its limbs; indeed, on a superficial view, it bears a striking resemblance to Linyphia pusilla; but the structure of the maxilla and the relative length of the 
legs have induced me to class it with the Theridia. It occurs under stones in the woods at Oakland, where I captured specimeris in March 1835.

The first individual I examined under the microscope was a female, and it presented an anomaly in organization which I never before witnessed in this class of animals; it had a supernumerary eye, situated between the two small ones constituting the anterior pair of the trapezoid. An instance of a deficiency of eyes in a female Thomisus cristatus has since fallen under my observation. This spider had the two lateral pairs only; the two intermediate, or smaller pairs, were altogether wanting, not even the slightest rudiments being visible.

\section{Genus, $\left.\begin{array}{l}\text { Neriene, } \\ \text { Neriene rubripes, }\end{array}\right\}$ mihi.}

Cephalothorax oval, convex, glossy, with furrows on the sides diverging from the upper part to the margins, and an indentation in the medial line of the posterior region. Mandibles powerful, conical, convex in front, divergent at the lower extremities, armed with two rows of teeth on the inner surface, and slightly inclined towards the pectus, which is heartshaped. Maxillæ strong, and inclined towards the lip, which is semicircular and prominent at the apex. These parts are of a red-brown colour, the mandibles, lip, and margins of the pectus being the darkest. Legs moderately robust, provided with hairs and a few fine spines; the first pair is rather the longest, then the fourth, the third pair being the shortest. These organs and the palpi are of a red colour. Each tarsus has three elaws at its extremity; the two superior ones are pectinated about two thirds of their length from the base, and the inferior one is inflected near its insertion. Eyes placed on black spots, and disposed as in the Nerience generally. Abdomen oval, convex above, projecting over the base of the cephalothorax; it is thinly covered with hair, glossy, and brownish black. Plates of the spiracles pale yellow. A curved process of a red-brown colour is connected with the sexual organs. Some individuals have the abdomen of a yellowish-brown hue, and the other parts, generally, lightercoloured.

Length, from the anterior part of the cephalothorax to the extremity of the abdomen, $\frac{9}{48}$ ths of an inch; length of the cephalothorax $T^{\frac{1}{2}}$; breadth $\frac{1}{16}$; breadth of the abdomen $\frac{1}{1^{2}}$; length of an anterior leg $\frac{1}{4} ;$ length of a leg of the third pair $\frac{5}{2}=$.

The male is somewhat smaller and darker-coloured than the female, but its legs are longer, an anterior one measuring $\frac{y}{2}$ ths of an inch. The maxillæ are remarkably convex externally immediately before the insertion of the palpi. The second joint of the palpi is curved towards the cephalothorax ; the third and fourth joints are short, the latter being rather the larger: the fifth is oval, convex and hairy externally, concave within, comprising the palpal organs, which are prominent, highly developed, complex in structure, and are of a dark red-brown colour. The fifth or terminal joints of the palpi have their convex sides directed towards each other.

This species was found at Oakland, under stones, in the autumn of 1834, by Mr. T. Blackwall.

\section{Neriene tibialis.}

This spider has the cephalothorax of an oval form; it is convex, glossy, prominent but obtuse before, where the eyes are situated, with an indentation in the medial line of the posterior region. Mandibles moderately powerful, conical, armed with teeth on the inner surface, and somewhat inclined towards the pectus, which is heart-shaped. These parts, with 


\section{Mr. Blackwall on undescribed Species of Araneidæ.}

the maxillæ and lip, are of a brownish black colour. The anterior and posterior pairs of legs, which are the longest, are equal in length, and the third pair is the shortest. Each tarsus is terminated by three claws; the two superior ones are slightly pectinated, and the inferior one is inflected near its base. The tibiæ of the anterior pair of legs are disproportionally strong, having the appearance of being swoln. The palpi are slender; the third joint is long and clavate; the fourth is elongated before into a narrow, oval process, hairy externally, which extends obliquely across the upper part of the fifth joint towards the inner side, but is terminated by a short, acute spine curved outwards: the fifth joint is oval, convex and hairy externally, concave within, comprising the palpal organs, which are highly developed and complicated in structure, having several corneous processes, one of which, on the outer side, at the extremity, is curved into a cireular form. Abdomen oval, convex above, projecting over the base of the cephalothorax ; it is thinly covered with hair, glossy, and of a brownish black colour. The plates of the spiracles are pale yellow.

Length, from the anterior part of the cephalothorax to the extremity of the abdomen, st th of an inch; length of the cephalothorax $\frac{s^{\prime}+}{1}$; breadth $\frac{1}{2} ;$ breadth of the abdomen $\frac{1}{3} \sigma$; length of an anterior leg $\frac{1}{7}$; length of a leg of the third pair ?

In March 1835 I captured a few specimens of this species, all of which were males, under stones, at Oakland.

\section{Neriene livida.}

Cephalothorax oval, convex, glossy, with several furrows on the sides diverging from the middle to the margins, and an indentation in the medial line of the posterior region. Mandibles powerful, conical, convex in front, near the base, armed with a few small teeth on the inner surface, and rather inclined towards the pectus, which is heart-shaped. Maxilla strong, convex underneath, and inclined towards the lip, which is somewhat of a triangular form truncated at the apex. Legs and palpi robust, and furnished with hairs and tine spines. These parts are of a red-brown colour, the lip, maxillæ. mandibles, and anterior part of the cephalothorax being the darkest. Each tarsus is terminated by three claws; the two superior ones are curved and deeply pectinated, and the inferior one is inflected near its base; the palpi have a curved, pectinated claw at the extremity. Abdomen oval, convex above, projecting over the base of the cephalothorax, and rather broader at the posterior than the anterior extremity; it is thinly covered with hair, glossy, and of a yellowish-brown colour, with a tinge of black. Plates of the spiracles pale-yellow.

Length, from the anterior part of the cephalothorax to the extremity of the abdomen, $\frac{1}{6}$ th of an inch; length of the cephalothorax $\frac{1}{1}$; breadth $\frac{1}{2}$; breadth of the abdomen $\frac{1}{12}$; length of an anterior leg $\frac{1}{5}$; length of a leg of the third pair $\frac{1}{7}$.

The male is smaller and darker coloured than the female, but the relative length of its legs is the same. The second joint of the palpi is curved towards the cephalothorax; the third and fourth joints are short, the latter projecting two obtuse apophyses, the larger one situated on the outer and the smaller one on the inner side : the fifth joint is oval, convex and hairy externally, concave within, comprising the palpal organs, which are highly developed, complex in structure, and of a dark red-brown colour.

This species is common on the under surface of stones in the neighbourhood of Llanrwst.

\section{Neriene furva.}

The cephalothorax is of an oval figure; it is convex, glossy, with slight furrows on the sides, and an indentation in the medial line of the posterior 


\section{Mr. Blackwall on undescribed Species of A raneidæ.}

region. Mandibles powerful, conical, vertical, convex in front, and armed with teeth on the inner surface. Maxillæ enlarged at the base, where the palpi are inserted, and inclined towards the lip, which is semicircular and prominent at the apex. Pectus heart-shaped. These parts are dark brown, with a slight tinge of red, the pectus, lip, and anterior part of the cephalothorax being the darkest. Legs and palpi robust, and of a red colour. Each tarsus is terminated by three claws; the two superior ones are pectinated about half their length from the base, and the inferior one is inflected near its insertion. The third and fourth joints of the palpi are short, the former, which is considerably the stronger, being convex in front; the latter projects two apophyses from its anterior extremity; one before, which terminates in a corneous point, and has a small, acute, corneous prominence on the inner side; the other underneath, which is provided with a comeous point on the outer side: the fifth joint is oval, convex and hairy externally, concave within, comprising the palpal organs; they are highly developed, complicated in structure, with a corneous process at the upper part curved outwards, and are of a dark red-brown colour. Abdomen oval, convex above, projecting over the base of the cephalothorax; it is thinly covered with hair, glossy, and of a brownish-black colour. Plates of the spiracles pale yellowish-white.

Length, from the anterior part of the cephalothorax to the extremity of the abdomen $\frac{1}{9}$ th of an inch ; length of the cephalothorax $\frac{1}{17}$; breadth $\frac{1}{2} \sigma$; breadth of the abdomen $y_{6}^{\prime}$; length of an anterior leg $\frac{1}{6}$; length of a leg of the third pair $\frac{1}{7}$.

I found one male only of this species, under a fragment of rock in a wood at Oakland, in June 1835.

$$
\begin{aligned}
& \left.\begin{array}{l}
\text { Tribe, Orbitel.a, } \\
\text { Genus, Linyphia, }
\end{array}\right\} \text { Latreille. } \\
& \text { Linyphia nigella. }
\end{aligned}
$$

Cephaiothorax oval, convex, glossy, with an indentation in the medial line of the posterior region; it is of a dark brown colour approaching to black. Mandibles long, powerful, armed with teeth on the inner surface, divergent at the extremities, of a deep hrown colour tinged with red, and inclined towards the pectus, which is heart-shaped, and of a brownish black hue. Maxilla strong, longer than broad, with the exterior angle, at the extremity, curvilinear; they resemble the mandibles in colour, and incline a little towards the lip, which is semicircular, prominent at the apex, and brownish black. Leys long and slender, provided with hairs and a few spines; their colour is pale yellowish brown, the thighs having a tinge of red. Each tarsus is terminated by three claws; the two superior ones are curved and pectinated, and the inferior one is inflected near its base. Eyes disposed in two transverse rows on the anterior part of the cephalothorax ; the intermediate eyes of both rows form a trapezoid, whose anterior side is considerably the shortest, and the lateral ones are placed obliquely in pairs, each pair being seated on a small eminence, and geminated; the posterior eyes of the trapezoid are the largest, and the anterior ones much the smallest of the eight. The third and fourth joints of the palpi are short, the latter, which is much the stronger, being prominent on the inner side, at the lower extremity: the fifth joint is of an irrregular oval figure, convex and hairy externally, concave within, comprising the palpal organs, which are highly developed, complicated in structure, having a small projection at the upper part, in front, and a large corneous spine, originating in the upper part of the under side, extending to the termination of the joint, where it is curved into a circular form, the extremity projecting $a$ little; the colour of these organs is dark reddish brown. 


\section{Mr. Blackwall on undescribed Species of Araneidæ.}

The convex sides of the fifth or terminal joints of the palpi are directed towards each other. Abdomen oval, convex above, projecting over the base of the cephalothorax; it is thinly covered with hair, glossy, and brownish black. Plates of the spiracles pale yellowish browr. Some individuals have a series of obscure, angular lines of a yellowish brown colour, whose vertices are directed forwards, extending along the middle of the upper part.

Length, from the anterior part of the cephalothorax to the extremity of the abdomen, $\frac{1}{8}$ th of an inch; length of the cephalothorax $\frac{1}{18}$; breadth $\frac{1}{2}$; breadth of the abdomen $\frac{1}{19}$; length of an anterior leg $\frac{11}{4}$; length of a ley of the third pair $\frac{1}{6}$.

Specimens of this species were procured under fragments of rock in the woods at Oakland, in September 1835 , but they were all males.

\section{Linyphia tardipes.}

The cephalothorax of this interesting species is oval, convex, glossy, depressed and somewhat rounded before, with an indentation in the medial line of the posterior region; its colour is reddish brown, with a broad band of blackish brown extending along each side. Mandibles powerful, conical, divergent at the extremities, and inclined towards the pectus; they are terminated by a long nail slightly curved at its extremity, and are armed with two rows of teeth on the inner surface, the anterior row being remarkably long and fine. Maxillæ strong, straight, and somewhat quadrate, having the exterior angle, at their extremity, curvilinear. Lip semicircular and prominent at the apex. The pectus, which is heart-shaped, is finely pointed at its posterior extremity. These parts are of a reddish brown colour, the pectus and lip being rather the darkest. Eyes placed on black spots on the anterior part of the cephalothorax; four are intermediate and form a square nearly, the two in front being the largest of the eight; the other four are disposed in pairs on the sides of the square; the eyes constituting each pair are placed obliquely on a small eminence, and are contiguous. The palpi are furnished with spines, and have a slightly curved, slender claw at their extremity; their colour is reddish brown. Leos moderately robust, supplied with hairs and a few fine, erect spines; they are of a reddish brown colour obscurely banded with brownish black; the first pair is the longest, the second and fourth pairs are nearly equal in length, and the third pair is the shortest. Each tarsus is terminated by three claws; the two superior ones are curved, and the inferior one is inflected near its base. Abdomen oval, convex above, rather broader at the posterior than the anterior extremity, and projects over the base of the cephalcthorax; it is thinly covered with hair, glossy, and of a reddish brown colour on the upper side with a few minute, whitish spots interspersed, and a series of large, brownish black blotches extending along each side of the medial line; these blotches unite, as they approach the spinners, and form transverse, curved bands; the sides are brownish black, minutely mottled with reddish brown; the under side is dark brown, or brownish black. Plates of the spiracles pale yellow. Conuected with the sexual organs is a large and very prominent, curved process of a dark red-brown colour; it is abruptly contracted in the curvature, and is recurved at the extremity, which is enlarged and deeply notched.

Length, from the anterior part of the cephalothorax to the extremity of the abdomen, $\frac{1}{6}$ th of an inch ; length of the cephalothorax ${ }_{T^{2}}$; breadth ${ }_{16}^{\frac{1}{6}}$; breadth of the abdomen ${ }_{T}^{1} z$; length of an anterior leg $z^{5} \neq$; length of a leg of the third pair $\frac{1}{6}$.

The male resembles the female in colour, and in the relative length of the legs, but their absolute length is greater, an anterior one measuring 


\section{Mr. Blackwall on undescribed Species of Araneidæ. 489}

7 ths of an inch. On the anterior part of the cephalothorax, about the region of the eyes, are some longish, black bristles, directed forwards. The third and fourth joints of the palpi are short, the latter being the stronger, and a long, slender bristle projects in front from the anterior extremity of the former: the fifth joint is somewhat oval, being gibbous on the outer margin, and having a large process, or apophysis, curved outwards, and notched at its extremity, directed upwards from its superior part; it is convex and hairy externally, concave within, comprising the palpal organs, which are highly developed, complex in structure, presenting several curved, corneous prosesses, and are of a red-brown colour. The fifth joints of the palpi have their convex sides turned towards each other.

In the autumn of 1834, I found specimens of this spider at Oakland, under detached pieces of rock imbedded in a light soil, to the inferior surface of which they attach their cocoons, usually two or three in number, by a small, fine web. The cocoon is flat on the side in contact with the rock, and convex, with a smail, depressed border, on the opposite one. It measures about ${ }_{1}^{1}$ th of an inch in diameter, is composed of white silk of a fine compact textnre, and contains, on an average, brtween thirty and forty spherical eygs of a pale yellow colour, not agglutinated together, but enveloped in delicately soft silk. This species fabricates a small, compact, horizontal sheet of web in the cavities beneath stones, on the under side of which it takes its station in an inverted position. It pairs in the month of September. An approximation to the Theridia may be traced in the disposition and relative size of the eyes.

\section{Tribe, Laterigrade, Latreille. Genus, Thomisus, Walckenäer. Thomisus luctuosus.}

Cephalothorax inversely heart-shaped, convex, depressed in the posterior region, and broadly truncated before; it is of a brown colour, veined with lines of a deeper shade, and has a fine line of yellowish white on the lateral margin; a short band of a yellowish white hue, bifid before, on each side of which is a spot of the same colour, situated on an irregular, black patch, occupies the medial line of that portion of the cephalothorax which is in contact with the abdonien, and a faint brownish white spot occurs on the inner side of the tubercles on which the anterior eyes of the lateral pairs are seated. Eyes disposed in front, in two transverse, curved rows, forming a crescent; the lateral eyes of both rows are larger than the rest, those of the anterior row being the largest of all, and are situated on projections of the cephalothorax. Mandibles short, strong, vertical, cuneiform. Maxillæ inclined towards the lip, which is triangular. Pectus oblong heart-shaped. These parts, with the legs and palpi, are of a dark brown colour, the legs being streaked and spotted with brown of a deeper shade, and yellowish white at the joints. The first and second pairs of legs, whose dimensions considerably exceed those of the third and fourth pairs, are nearly equal in length, the second pair being slightly the longer; and the longitudinal extent of the fourth pair surpasses that of the third. Each tarsus has two curved, deeply pectinated claws at its extrenity. Abdomen oval, depressed, wrinkled, broader at its posterior than its anterior extremity, and projects over the base of the cephalothorax; its colour is dark brown obscurely mottled with pale brown and yellowish white, particularly on the upper part. Plates of the spiracles reddish brown.

Length, from the anterior part of the cephalothorax to the extremity of the abdomen, $\frac{1}{4}$ th of an inch ; length of the cephalothorax $\frac{t}{3}$ th ; breadth

Third Series. Vol. 8. No. 49. June 1836. 3 D 


\section{$490 \mathrm{Mr}$. Blackwall on undescribed Species of Araneidr.}

$\frac{1}{T}$; breadth of the abdomen $\frac{1}{7}$; length of a leg of the second pair $\frac{1}{3}$; length of a leg of the third pair $\frac{1}{4}$.

I discovered the female of this species, which seems to belong to the section Cancroides, in September 1834, in the woods at Oakland, on the trunks of trees which had heen felled. In July it constructs a lenticular cocoon of white silk, of a compact texture, measuring about $\frac{1}{7}$ th of an inch in diameter, in which it deposits between 80 and $\mathbf{9 0}$ spherical eggs, of a pale yellowish white colour, not agglutinated together. The cocoon is often placed between two leaves connected by a slight tissue of silk, forming a kind of sack, usually containing the female, which sits upon the cocoon and is greatly at tached to it.

$$
\begin{aligned}
& \left.\begin{array}{l}
\text { Tribe, Citigrada, } \\
\text { Genus, Lycosa, } \\
\text { Lycosa exigua. }
\end{array}\right\} \text { Latreille. } \\
& \text {. }
\end{aligned}
$$

Cephalothorax large, hairy, somewhat oval, compressed before, with depressed, sloping sides, and a narrow indentation in the medial line of the posterior region; its colour is dark brown, with three longitudinal bands of a pale yellowish brown tint, one extending along each side, and the third occupying the carina. Mandibles strong, conical, armed with a few teeth on the inner surface, reddish brown, and inclined towards the pectus, which is heart-shaped, of a very dark brown colour, approaching to black, and is thinly covered with whitish hairs. Maxillæ short, powerful, straight, enlarged and rounded at the extremity, and of a pale reddish brown colour. Lip quadrate, and of a dark, dull brown colour, being palest at the apex. Eyes unequal in size; four, which are minute, form a row in front, the two exterior ones being the smallest; the other four are placed on the sides of the anterior part of the cephalothorax, and form a square nearly, the anterior pair being the largest of the eight. Legs and palpi long, moderately robust, and provided with hairs and strong spines; they are of a pale reddish brown colour, with spots and longitudinal streaks of a brownish black hue on the upper part and sides; these spots and streaks are most conspicuous on the thighs, and on the second joint of the palpi. The palpal claw is curved and pectinated. Each tarsus has two curved, deeply pectinated claw's at its extremity. Abdomen oval, hairy, convex abcve, projecting cver the base of the cephalothorax; it is dark brown on the upper side, with three yellowish white spots in front, the intermediate one, which is the largest, and is faintly bordered with brownish black, extending backwards nearly half the length of the abdomen; on each side of the medial line, on the posterior half of the abdomen, occurs a series of alternate blackish and white spots, the latter being much the smaller; the two series, which are rather obscure in some specimens, converge to the spinners, where they meet; the sides are yellowish brown, spotted with dark brown; the under side is pale yellowish, or reddish brown. Plates of the spiracles very dark brown.

Length, from the anterior part of the cephalothorax to the extremity of the abdomen, $\frac{1}{1}$ th of an inch; length of the cephalothorax $\frac{1}{8}$; breadth $T_{T}^{1}$; breadth of the abdomen $\frac{1}{T^{\circ}}$; length of a posterior leg $\frac{11}{24}$; length of a leg of the third pair $\frac{3}{10}$.

The male is rather smaller than the female, and darker coloured, but the relative length of its legs is the same. The third and fourth joints of the palpi are short, the latter being the stronger of the two : the fifth joint is oval and pointed at the extremity, which is armed with a small claw; it is convex and hairy externally, concave within, except at the end, which is solid, and comprises the palpal organs; they are highly developed, com- 
The Rev. P. Keith on the Conditions of Germination. 491

plex with corneous processes, and are of a very dark reddish brown colour.

This species occurs in pasture fields in Denbighshire. In the month of June the female spins a lenticular coconn of yellowish or greenish brown silk, of a compact texture, with a whitish margin of a slighter texture; it contains between 50 and 60 yellowish white eggs of a spherical figure, not agglutinated together. The cocoon, which is always connected with the spinners of the female, and is carried along with her, measures about $\frac{1}{6}$ th of an inch in diameter; when the young quit it they attach themselves to the body of the mother.

Oakland, Denbighshire, 1836.

LXXXIV. Of the Conditions of Germination, in reply to M. DeCandolle. By the Rev. P. Kerth, F.L.S.*

$\mathbf{N}$

OTHING can be so gratifying to an author as the commendation that comes from a critic of acknowledged talent and learning-"laudatus a laudato viro." But we, the of $\pi 0 \lambda \lambda \circ$ of botanical scribblers, ought, perhaps, to rest satisfied, and to think ourselves very well off if a first- or secondrate wrangler in the science condescends to take notice of us, if it were but for the purpose of giving us a rap on the knuckles.

In my System of Physiological Botany published in 1816+, I enumerated five conditions as necessary to the process of the germination of the seed, and thought I had adduced good grounds for the said enumeration. Yet its accuracy has been impugned by a great botanist, and my five conditions reduced to three. I ought, perhaps, to submit in silence, and take in good part the correction of a great master; but as I am not satisfied of the soundness of the views of my corrector, I will venture to vindicate my original statement.-Proceed we now to the article itself.

I. The first condition necessary to germination is the maturity of the seed. Unripe seeds seldom germinate, because their parts are not yet prepared to form the chemical combinations on which germination depends. This fact M. De Candolle denies, saying that “ M. Keith ne s'est pas exprimé avec precision lorsqu'il a posé la maturité de la graine, pour première condition générale et nécessaire à la germination"; and adding that Senebier and Treviranus succeeded in making green peas to germinate a short time before they were absolutely ripef. If $\mathrm{M}$. DeCandolle had read to the end of the paragraph which he criticizes, he would have seen that the identical exception which he specifies is mentioned by

* Communicated by the Author.

+ Vol. ii. p. 3.

+. Physs. Vég. ii. 662.

3 D 2 